\title{
The Vanishing Viper: themes from a meeting to consider better conservation of Vipera berus
}

\author{
ANGELA JULIAN ${ }^{1 *} \&$ RICK J. HODGES ${ }^{2}$ \\ ${ }^{1}$ Amphibian and Reptile Groups UK, 82, Gidley Way, Horspath, Oxford, OX33, 1TG, UK \\ ${ }^{2}$ Kent Reptile and Amphibian Group, c/o KMBRC, Brogdale Farm, Brogdale Road, Faversham, Kent ME13 8XZ, UK \\ *Corresponding author e-mail: angela.julian@arguk.org
}

\begin{abstract}
Vanishing Viper 2019' was organised in the wake of continuing evidence for declines in British populations of the northern viper or adder (Vipera berus). The meeting included British participants as well as those from other European countries, whose insights suggest that the drivers of adder declines in mainland Europe are similar to those in Britain. Consequently, we stand to benefit from their knowledge and experience. It was concluded that if adder declines continue at the present pace then Britain may be left with a few large, flourishing populations, but that many of the smaller populations will be lost as appears to have happened in Belgium, France, Germany and The Netherlands. The meeting considered a range of conservation actions including improvements to habitat management, the creation of adder 'ARKs', population restoration by genetic or demographic enhancements, community level promotion and outreach, and opportunities for new policy-driven environmental schemes. It is recommended to create a national Adder Working Group to help crystallise and prioritise the main issues and a larger, more informal Adder Network to link and co-ordinate adder researchers and land managers to ensure a free flow of ideas, information and advice. Our chances of success in these ventures will be all the greater if we continue to share experience with our European neighbours.
\end{abstract}

\section{BACKGROUND}

I June 2019, herpetologists and land-managers met at Bangor University in North Wales to consider the conservation of the northern viper or adder (Vipera berus). 'Vanishing Viper 2019: A European approach to developing an adder conservation strategy' had 110 participants from Great Britain and elsewhere in Europe (Belgium, France, Germany, Sweden, Switzerland and The Netherlands). The meeting was introduced by a message of support recorded by local celebrity naturalist, Iolo Williams, and by a parade through the auditorium of 'Gwiber' the giant paper adder created by school children in Wales as part of the 'Adders are Amazing!' Project (Fig. 1). For the full meeting agenda see ARG UK (2019).

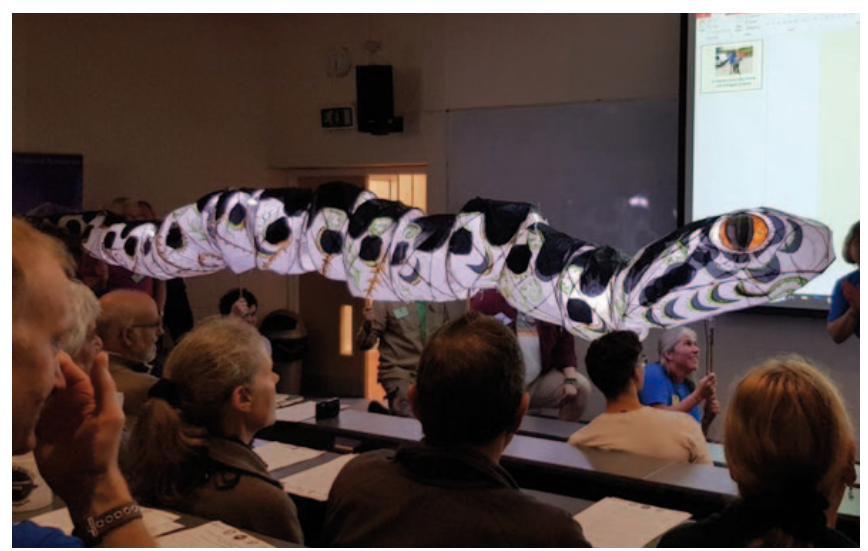

Figure 1. 'Gwiber', a Chinese-lantern adder created by school children for the 'Adders are Amazing!' project in Wales, parading through the meeting auditorium
The rationale for VV 2019 stems from long-held concerns that British adder populations have been declining over many years. In November 2011, the Kent Reptile and Amphibian Group (KRAG) organised the first national adder-focused meeting in Kent. With over 100 delegates, the meeting passed a unanimous motion stating that "The adder is in more urgent need of new conservation efforts than any other reptile or amphibian species in Britain", and a subsequent statistical study by Gleed-Owen \& Langham (2012) suggests that declines of this species may have been by as much as $39 \%$ since the 1980 s.

In 2016, a second national meeting 'Vanishing Viper: Priorities for adder conservation' was organised by the Reptile and Amphibian Group of Somerset (RAGS) with ARG UK and Amphibian and Reptile Conservation (ARC). VV 2016 brought together 150 conservationists who reviewed the evidence of researchers, landowners and statutory bodies to clarify the options for adder conservation. A consensus from all the issues raised was achieved at the meeting using a mind-mapping process, which was refined through a Delphi style analysis to provide a logical starting point to develop a shared understanding of the conservation concerns. The analysis was included in the first session of VV 2019. This report on VV 2019 gives an overview of the meeting and consolidates the subsequent discussions and e-mail exchanges with the intention of stimulating greater efforts for adder conservation.

\section{MEETING SESSIONS}

\section{What are the concerns?}

Richard Griffiths (DICE, U. of Kent) presented the findings 
of the 'VV 2016' mind mapping exercise. Thirty eight conservation issues were identified as important, and these were consolidated into eight themes (Fig. 2). The vast majority of conservation issues identified were ranked as 'important', but none were regarded as being tackled well. The biggest gap between 'importance' and 'delivery' relates to habitat management (Fig. 2). The impression from the analysis was that there is no 'silver bullet' that will halt adder declines, but instead improvements in delivery are needed across a range of key issues where there is room for renewed focus and innovation.

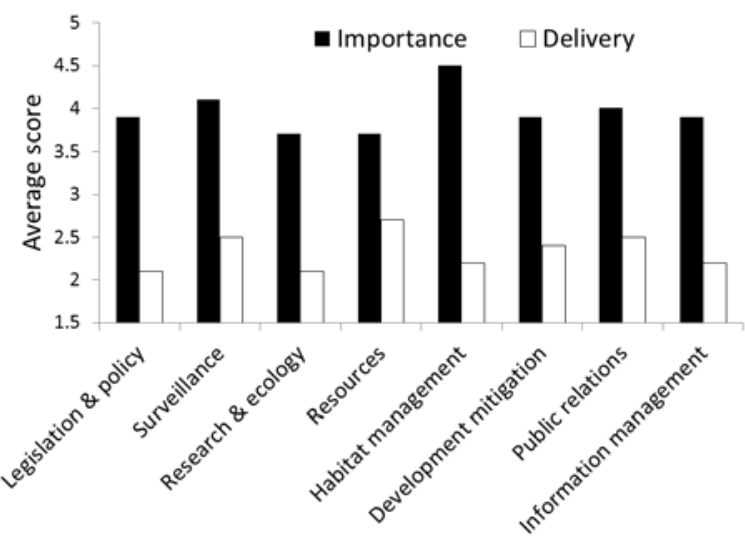

Figure 2. Summary of the importance and delivery of eight key conservation themes based on 'expert' consensus at 'Vanishing Viper 2016'. Importance: 1= 'unimportant'; 5= 'very important' ; Delivery: $1=$ 'not done'; $5=$ 'done very well'

Concerns about poor habitat management and increasing predation were highlighted by Nigel Hand (Central Ecology). Over the last 50 years, there have been serious declines in adder populations in the English counties of Herefordshire, Worcestershire and Gloucestershire and extirpation in the counties of Warwickshire, Oxfordshire and Nottinghamshire. These declines are often associated with land use changes, including large-scale mechanised forestry operations. Telemetry has been used to understand adder movements, barriers to dispersal, linkages, and the effects these may have on populations. This has highlighted the secretive, underground habits of the adders, even during the summer months, making them vulnerable to injury from the use of heavy machinery. If prior to large-scale management land managers were more aware of the landscape features essential to adder survival, such as hibernacula, important foraging and birthing areas, and corridors of connectivity, then this damage could be limited. To provide this information across large tracts of land would require considerable effort, but could be achieved if there was a focus on selected sites. This is the rationale for establishing 'ARK' sites for adders. Also highlighted were the clear impacts of predators such as wild boar, pheasants, corvids and raptors; fire (wild fire and planned burns on adder sites); recent landscape-scale rewetting projects; and, the unknown potential of accidental exotic snake releases to transmit novel pathogens.

Inbreeding is another potential cause for population declines and has been demonstrated in a small isolated adder population in Sweden (Madsen et al., 1999). In this context, Sarah Ball (Institute of Zoology) reported on the genetics of adders in the West Midlands where, in the small populations sampled, a high proportion of individuals were closely related. Nevertheless, the study populations showed no detectable loss of heterozygosity, which is in line with published levels for mainland Europe, even for small isolated populations with a high risk of decline. This suggests that reliance on standard indicators of inbreeding and diversity may be masking demographic factors that make small adder populations vulnerable to extinction. Consequently, risks of extirpation probably relate more to the small size of populations per se than to inbreeding.

\section{Managing adder sites sympathetically}

Presentations in this session gave an opportunity to learn from the experiences and practices of land managers concerned, at least in part, with adder conservation as well as managing many other, sometimes conflicting, commitments.

Tom Simpson (Natural England) used his presentation to address the question 'Do adders have a future in the Wyre forest?' which since the 1970s has suffered a mysterious long-term adder decline. Previously, adders were described as abundant in the Wyre Forest and its surrounds, even under a heavily industrialised landscape (charcoal production, tanning and railway), but the population has now crashed and in 2018 only 39 animals were recorded at 11 locations, down from a peak of 267 animals at 61 locations in 1991. This has prompted an urgent need for action that has included: improving adder habitat by positive management practices (Figs. 3a \& b) such as creating open spaces, corridors linking populations, brash piles to create habitat corridors on newly cleared sites, a reduction in burning, and excluding people from sensitive areas (using fences and signs, and by making footpaths unsuitable). The impact of these practices will be monitored.

Next, Geraint Jones of the Pembrokeshire Coast National Park Authority explained that in the National Park the habitat suitable for adders is often squeezed into a narrow strip between intensively farmed land and rocky coastal cliffs. The justification for active management of the latter area has been compelling. During the last 20 years or so, a partnership including landowners and conservation organisations has succeeded in re-introducing positive, proactive management to the coastal zone. Additionally, advice and practical assistance are available from two voluntary umbrella organisations. The Pembrokeshire Grazing Network (PGN) helps to source appropriate livestock for conservation grazing, and the Pembrokeshire Wildfire Group (PWG) provides a lead on wildfire issues and best practice for controlled burning. PWG is a partnership of farmers and graziers, the Mid and West Wales Fire and Rescue Service, and local conservation bodies. It focuses on reducing uncontrolled wildfires and ensures that controlled burns are planned in accordance with relevant regulations. Informed and sensitive implementation of management actions (especially controlled burning) is critically important, and this is being achieved with the help of Pembrokeshire 

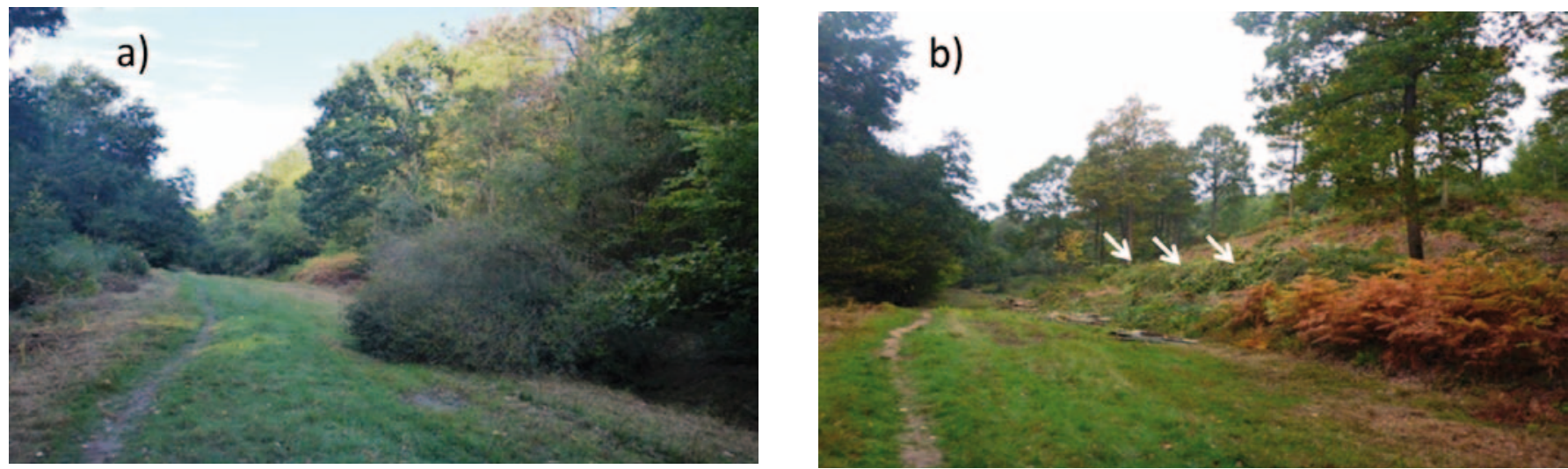

Figure 3. Improvement of a ride and adjoining bank in the Wyre forest a) unimproved ride, $\mathbf{b}$ ) the same ride with bank opened up to basking, but with plenty of cover remaining and brash piles made of birch and oak crowns (arrows) placed along the bank to provide protection from people and dogs

Amphibian and Reptile Group through the development of predictive geo-mapping of adders. The geo-mapping identifies likely adder habitats and hibernacula to inform the decisions of land managers and even the fire rescue service, which can now access the maps via mobile terminals.

Finally, Kevin James of the Lincolnshire Wildlife Trust (LWT), presented the example of the management of the Woodhall Spa airfield cluster. As land manager, LWT encounters the widely reported problems of juggling the interests of different species and often conflicting targets, especially when maintaining 'favourable condition' on Sites of Special Scientific Interest (SSSI). Significant financial support for the management of wildlife sites comes from agri-environment schemes. Unfortunately, these schemes are directed at farming rather than conservation, which has resulted in many Wildlife Trusts being unable to enter the schemes, or in some cases having to consider changing their management practices in order to fit into the criteria. There are also difficulties with negative public perceptions such as with essential work such as tree felling, and the negative press coverage of adder bite incidents.

\section{The Northern European Perspective}

This session provided some fascinating insights into the situation elsewhere in Europe, where the drivers of adder declines appear similar to those in Britain, and where insights from long-term research offer potential solutions to our own problems.

Ina Blanke (Independent consultant) described the situation in Germany where the adder is considered a rare species restricted to the cooler areas. Stable populations still exist in parts of the Baltic Sea coast and at higher altitudes. Elsewhere, they are considered critically endangered due mainly to habitat loss in moorland (raised and lowland bogs), heathland, and the formerly large peatland complexes that are now much reduced due to land reclamation, peat extraction, and drought. The situation continues to deteriorate as there is increasing pressure from traffic and infrastructure development, intensive agriculture, particularly grazing that is supported by current agri-environment schemes, peat extraction which continues under long-term contracts, and climate warming exacerbating dehydration. Other concerns include predation from exploding populations of wild boar, and site specific interventions such as the removal of purple moor grass that otherwise provides vital cover for adders. On nature reserves, a few remedial measures are being implemented to try and reverse this decline. Habitat is being improved with the creation of forest clearings and rewetting (formerly disastrous in the way it was carried out, but more sympathetic nowadays). Pond creation is another important measure, since wetlands support prey species such as moor frogs. But the process needs to be ongoing, and more reptile sympathetic conservation measures are urgently needed, to which end a handbook for 'Reptile Friendly Management' will be published soon.

Dirk Bauwens and Katja Claus (U. of Antwerp) presented their 20-year study of an exceptionally large and stable adder population in the Groot Schietveld, military training area in northern Belgium. The habitat comprises a mosaic of lowland heaths, moorland ponds, woodlands and pastures over an area of ca. 1570 ha, but is entirely isolated from other adder populations. Using mark-recapture methods the group has built an extensive data-set of around 7300 records of some 3500 individual adders, from a population that at any one time numbers several thousand snakes. Adult adders undertake seasonal migrations between 'winter' and 'summer' habitats, where they go to forage and build up their fat reserves on the wet flushes, where prey is more plentiful than in the nutrient-poor 'winter' heathlands. Whilst adult adders are most easily observed in the 'winter' habitats, the immature and non-reproducing animals appear to spend most of their time in feeding habitats near, but outside of, the heathlands. The research also highlighted some important features of the adders' life cycle. Overall, the study found no evidence for agedependent differences in yearly survival rates or between reproducing and non-reproducing females. Most females reproduce for the first time when they are 4 years or older, after this giving birth at 2-3 year intervals. However, on average females produced only 1.3 litters during their entire reproductive lifetime. A key finding is that overall population growth is most sensitive to the survival rates of immature adders. This is an important message, and indicates that attention should be given equally to both the important winter (heathland) habitats, where the adult 
snakes are most easily observed near their hibernacula, and the often more neglected moist summer habitats that are so important for the immature adders. Special care is also required to maintain the migration routes between these two habitats.

Rolf van Leeningen (Reptile, Amphibian \& Fish Conservation Netherlands - RAVON) indicated that The Netherlands was similar to Belgium with two large unbroken clusters of adder populations restricted to protected areas of heathland and raised bog. Research on the 800 ha Hijkerveld reserve also shows seasonal movement of adders between different habitat types. During the winter they inhabit the heathland areas, but in summer they move to wetter areas with greater prey availability. As elsewhere in Europe, habitat loss is the main threat to adders in The Netherlands, and this is being mitigated by a major project, 'Viper Verbindt' (Viper Connect) in the east of the country which aims to increase, connect and restore habitat for adders, whilst also benefitting other species. In addition, a special volunteer adder working group 'Werkgroep Adderonderzoek Nederland' (WAN), set up by RAVON, plays an important role in collecting research data that is entered into a new snake portal web application (www.snakeportal.org). Data can be stored, analysed, exported into GIS applications, and photos of head scales uploaded and compared for individual recognition. The user manual and internal workings are both available in English. Our second Dutch speaker of the day, Marnix de Zeeuw (Statistics Netherlands) introduced TRIM (TRends and Indices for Monitoring data). TRIM is a statistical package for evaluating the conservation status of a species by calculating population trends and estimating population numbers. These numbers are based on repeated counts at various sites while counts may be missing for certain sites at certain times. Estimation depends on a model-based imputation method. TRIM has been rebuilt as an R package, RTRIM. RTRIM can work with multiple data sets and is a powerful tool for developing a broader European approach to monitoring and conserving adders. The package is available on the Comprehensive R Archive Network website (CRAN, 2019) and a manual and two articles that discuss the method are available on the Statistics Netherlands website (CBS, 2019).

Gaëtan Rey (Conservatoire d' Espaces Naturels, Nord Pas de Calais) presented the situation in the Haut de France, where adders are critically endangered. Genetic studies in 2010 indicated poor genetic diversity, although interestingly these animals are genetically closer to Belgian populations than the rest of France. Adders are a low priority for conservation and often ignored by site managers, who have little knowledge of their distribution on their sites, and as a consequence animals are frequently harmed by over-grazing and unsympathetic habitat work, particularly mechanical scrub clearance that damages hibernacula. An additional major issue is of persecution, since adders are widely disliked and feared. A number of regional action plans (2012-28), have been set up to try and redress these issues and have included all relevant stakeholders in discussions. The aims of these plans are threefold: to train volunteers to monitor adder populations to improve knowledge; to conserve existing populations by developing more sympathetic land management practices, e.g. lower impact grazing regimes; and, to improve public perceptions through an outreach campaign. In 2018, a National Viper Working Group was created in France for both $V$. berus and $V$. aspis. This aims to develop a national monitoring programme, more sympathetic management practices, and work with land managers to improve viper protection nationally.

On behalf of Sweden, Thomas Madsen (U. of Wollogong) presented observations from two sites: Smygehuk, and the island of Hallands Väderö, which have been under investigation for nearly 40 years. At Smygehuk in the late 1980s, the small population of adders began a gradual decline and deformed neonates were detected. This suggested the negative impacts of inbreeding. As a potential solution, in 1992 twenty male adders were introduced into the population (Fig. 4). From 1998 onwards the population recovered (Fig. 4). Genetic studies using whole genome sequencing have demonstrated an increased diversity of genes resulting from the introduction (Fig. 5) and more detailed study has suggested that this has resulted in greater heterozygosity in at least the genes involved in innate immune responses to disease. Interestingly, adder numbers fell dramatically again in 2009/2010 but this bottleneck apparently had no lasting impact on either numbers in subsequent years (Fig. 4) or genetic diversity when assessed in 2017 (Fig. 5).

In contrast to the Smygehuk population, the isolated population on the island of Hallands Väderö has maintained high levels of genetic diversity despite the 200 adders on the island being isolated for 6,000 years. This implies that small isolated populations will not necessarily become inbred in the long-term. This is related to the adder breeding system. Adder populations have low fecundity and low vagility and might therefore be expected to be prone to inbreeding, but female adders are adapted to avoid this. One adaptation is that a single female may mate with several males before the eggs are fertilised (polyandry) resulting in litters with higher levels of genetic variation. Furthermore, Thomas Madsen's own insights suggest that the eggs themselves are responsible for sperm selection in a way that maximises heterozygosity. Consequently, only if populations are founded on a very narrow genetic base does this lead to inbreeding, characterised by still births and deformities. Such observations have implications for the sustainability of genetically enhanced populations. Once successfully enhanced, the adder breeding system should then, at least theoretically, be able to maintain genetic diversity without further intervention.

There was a further important observation from Sweden. Adders may be seriously limited by climate variations, a good example being the exceptionally hot dry year of 2018, when two populations in Sweden lost access to both surface water and dew. This led to a reduction in numbers of males by $80 \%$ at one site and $50 \%$ at the other. In addition, survivors had a $20 \%$ reduction in residual body mass indicating that feeding had been disrupted. 


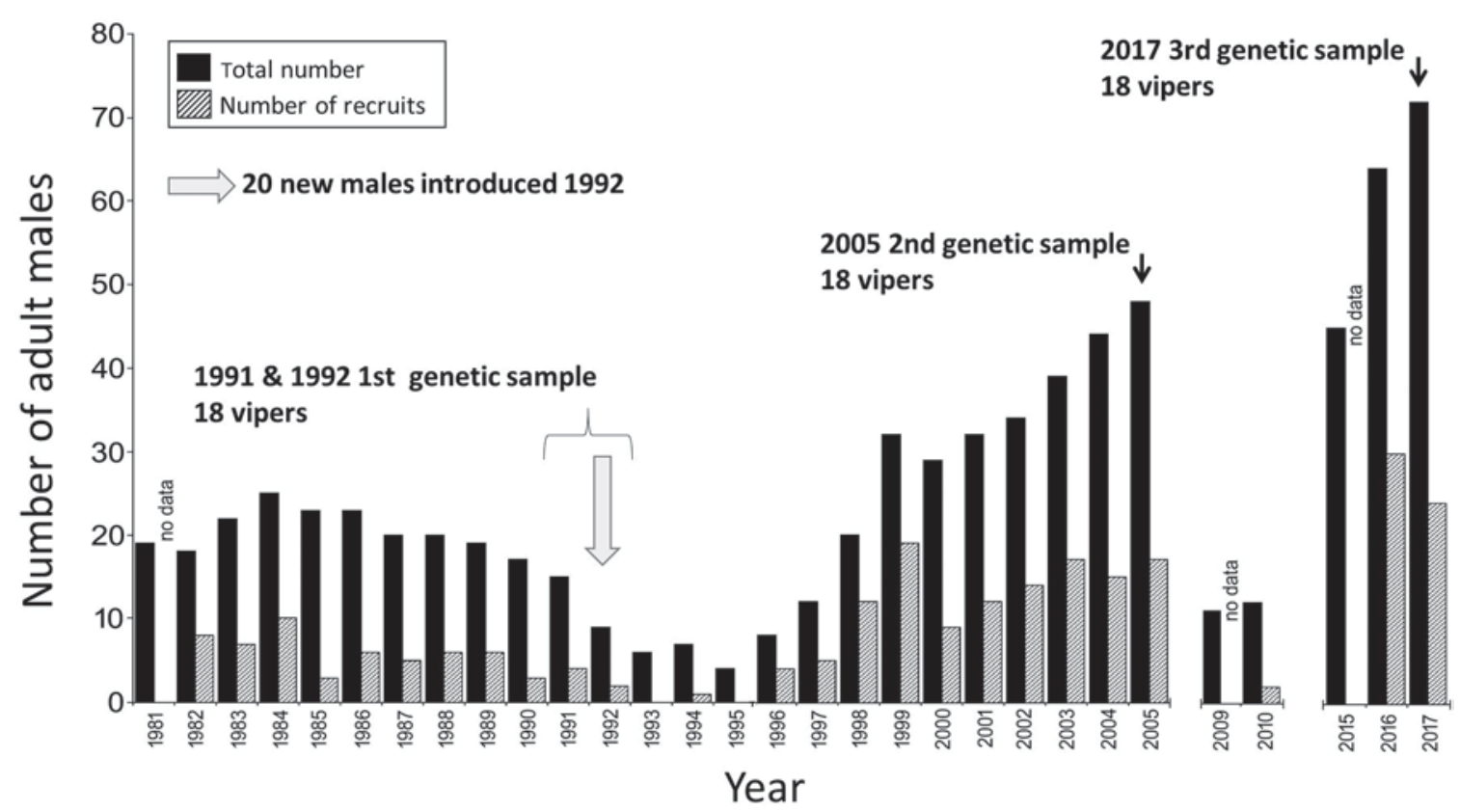

Figure 4. Genetic enhancement of a small $V$. berus population in Smygehuk, after 20 males were introduced in 1992 . Population restoration is noticeable from 1998. Samples for genetic analysis were taken in 1991/1992, 2005 and 2017 (see Fig. 5). The introduced males were not included in the counts. In 1995, the surviving 8 introduced males were returned to their natal population.

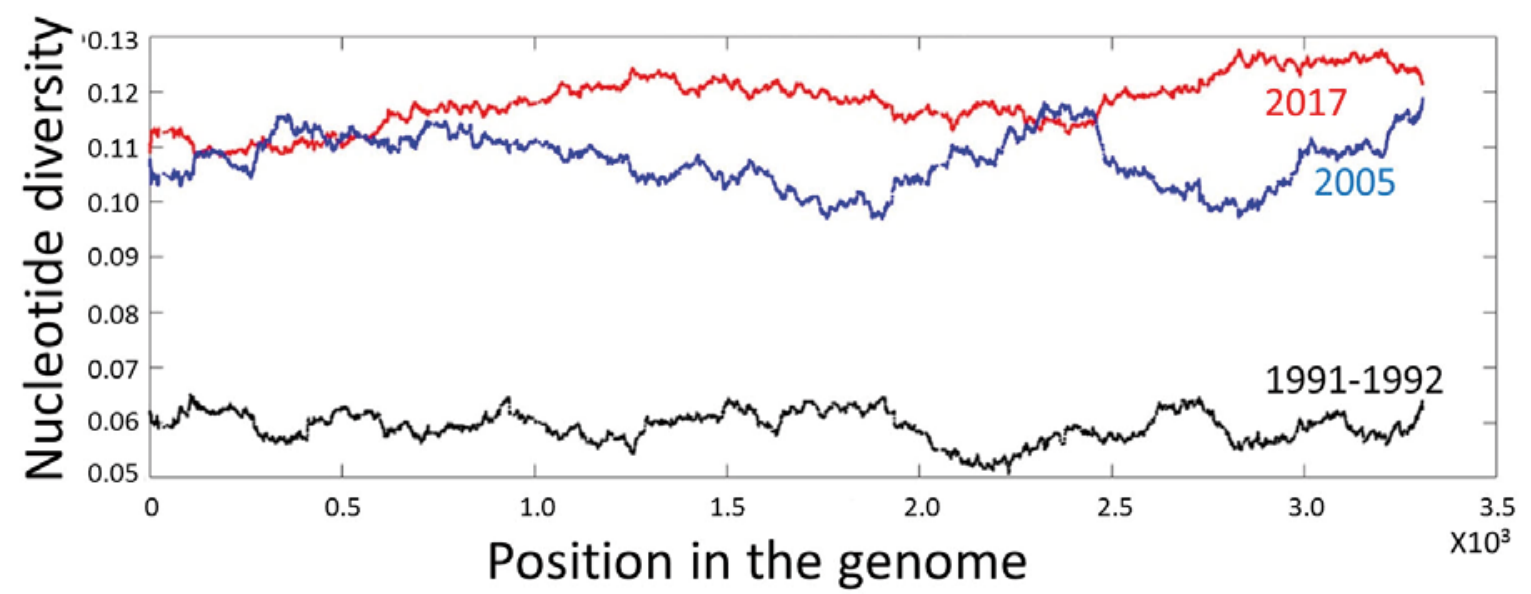

Figure 5. The genetic effect of introducing novel genes into the Smygehuk population of $V$. berus. Smoothed Manhatten plot of nucleotide diversity showing a highly significant increase in genetic diversity from 1991-1992 to 2005 and 2017.

This emphasises the potentially very damaging impact of periods of hot dry weather, which are expected to become more prevalent with future climate change.

\section{Engaging volunteers and communities}

Improving the public perception of adders is potentially a significant component in any strategy to help protect the species. To the naturalist community, adders are already a wildlife icon along with the red squirrel, otter and hedgehog, but in the wider population there is still a long way to go. This session indicted how we might engage people using the creative arts and how we should deal with the fact that adders are venomous.

The 'Adders are Amazing!' project, which was presented by Sam Langdon (ARG UK), is an excellent example of how a programme of community engagement can improve public perceptions. The project has piloted a range of activities to change the attitudes of local communities in West Wales by combining scientific engagement with artistic elements such as creating Gwiber the giant paper adder (Fig. 1), creating adder stone trails, and producing a variety of other art works such as the adder quilt (Fig. 6).

The project has now engaged almost 2,000 members of the local community of all age groups with activities in seven local schools, as well as with more mature members of the community, e.g. University of the 3rd Age (U3A), Womens' Institute, and local craft, wildlife and history groups. To measure the impact of the programme, attitudes towards adders were assessed in 263 children aged 5-11, before and three months after each school had received between 0.5 10 hours of input from the ARG UK project leader and a local artist. The intervention showed a significant improvement in attitudes towards adders, more so in older children, even when participants maintained a dislike of these snakes. 


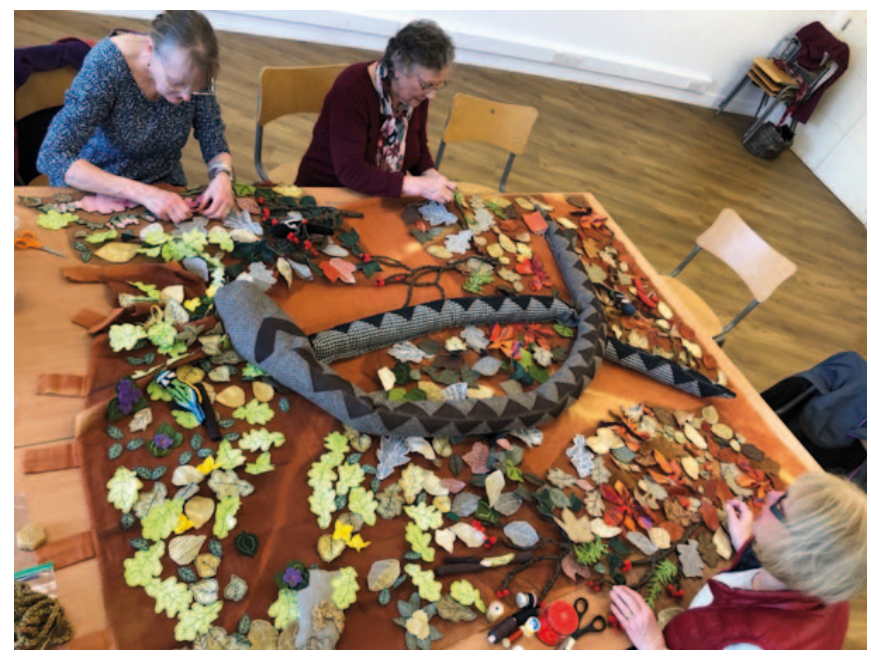

Figure 6. Creation of a quilt, coloured with natural dyes extracted from plants collected in the adder's habitat, celebrating the species as part of the 'Adders are Amazing!' project

This change may reduce adder persecution later in life. The position of the adder relative to other species was also assessed after three months intervention and it rose from number six to number three, but still behind the dormouse and curlew.

'Adders are Amazing!' has shown that it is possible to change attitudes without direct experience of adders, and that creative activities and 'fun' types of engagement really do improve perceptions. Nevertheless, those wishing to improve public perception of adders must take into account that the species is venomous. This was considered by Wolfgang Wuster (U. of Bangor) who indicated that to be realistic conservation of adders requires reconciling the needs of an animal in chronic decline with hostile public perception grounded in fear. This fear is often nurtured by sensationalist press coverage when people or dogs are bitten. Addressing this issue requires a rational assessment of the risk posed by the adder to the public in general, but also of the dangers posed when a person is actually bitten. In public health terms, the adder poses a negligible risk. For PR purposes, this can be compared to everyday risks the general public can more readily understand, e.g. a member of the public is 10,000 times more likely to choke to death on a piece of food than to die of an adder bite. However, the risks of an actual bite must not be understated; while the majority are relatively trivial, a significant minority of bites can give rise to serious illness, and a small proportion are life-threatening. It is important for our own credibility not to down play the risks as in some cases (15\% in Sweden) bites can be severe and even life threating. Adder bites are not like a bee sting, and are also unpredictable so that we never know in advance how serious the effects will be. Ironically, a survey of participants at the meeting showed that those working with adders were the worst culprits for not seeking medical attention, for most their strategy was to go home and 'wait and see' rather than immediately attend an accident and emergency unit as advised.

Reducing negative press coverage requires that the frequency of bites be lowered by public education in bite prevention, and by ensuring that those willingly interacting with snakes take appropriate precautions. On the one hand, fact-based outreach is needed to avoid the trap of suggesting that adder bites are not serious. On the other hand, couching public education in inclusive language likely to elicit empathy with adders, rather than fear and hostility, may play an important role. One important area is public signage, which may often be expressed in terms that encourage dislike and fear (Fig. 7a) which in fact could be reimagined in terms that encourage respect and appreciation (Fig. 7b).

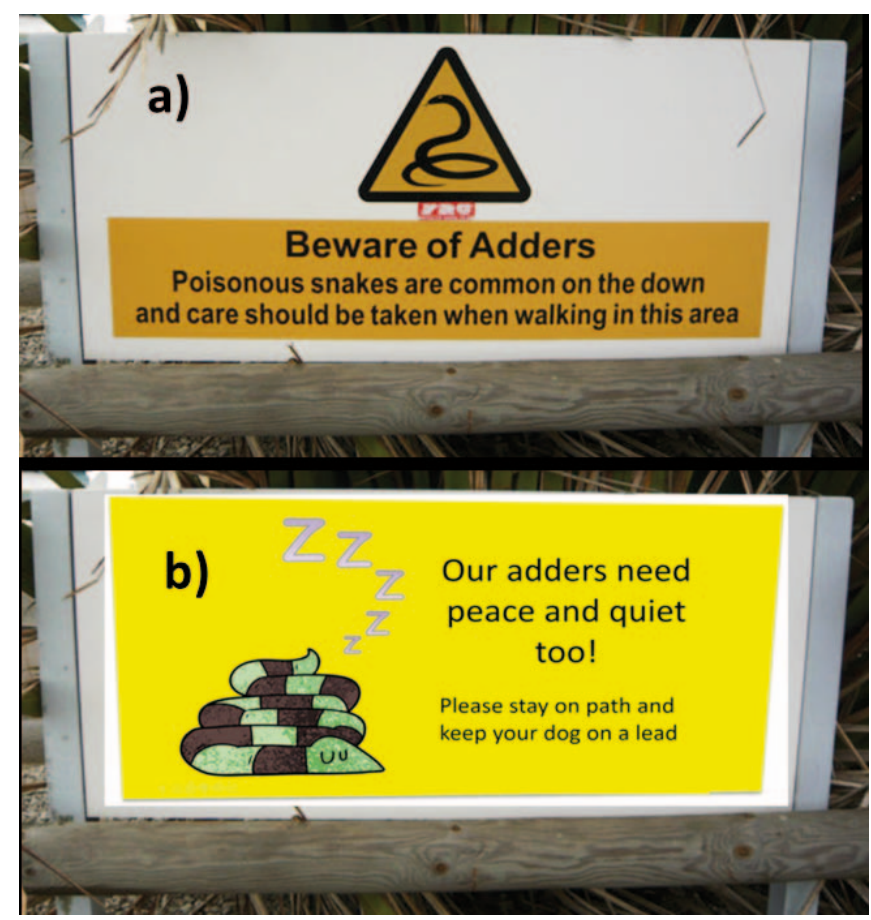

Figure 7. Adder warning signage could be improved to make the public more sympathetic towards the species, a) A relatively negative message in actual use, b) The type of message that could evoke a more sympathetic response

Volunteer recording effort plays an important role in assessing the conservation status of the adder. Emma Gardner (U. of Reading) reported on ARG UK's 'Make the Adder Count' survey that records population trends for adders in Britain based on springtime emergence counts. Counting began in 2005 when volunteer surveyors were asked to make three or more spring visits each year to their survey sites, whilst also noting any positive and negative factors that could be affecting the adders. Between 2005 and 2016, 181 surveyors provided information on 260 sites. Of these sites 129 contributed data for three or more years and these were used to derive average population trends over time. The data confirmed that on average, sites with small populations (where surveyors typically record peak counts $<10$ individuals, $\mathrm{N}=117$ ) declined by $55 \%$ over the 11 year monitoring period. By contrast, sites with large populations (site with mean peak counts $>10$ individuals, $N=12$ ) on average showed a $33 \%$ increase over the same period. If these trends are representative of Britain as a whole then within 15-20 years adders will become 
restricted to just a few sites with a large population. Public pressure/disturbance was reported as the most frequent negative factor, affecting $48 \%$ of sites, followed by habitat management and habitat fragmentation. Habitat management was reported as having negative impacts almost as frequently as positive impacts, suggesting that many management plans do not adequately consider the requirements of adders, a conclusion in agreement with the mind mapping exercise mentioned earlier.

\section{Adder conservation the way forward}

The final session considered how data collected by volunteers can be made to meet the needs of conservation planning, and what initiatives are in place now, or will be in the near future, to improve the status of the adder in Britain.

Steve Langham (Surrey Amphibian and Reptile Group - SARG) presented SARG's experience in developing an integrated approach to using volunteer survey and monitoring effort to drive conservation outcomes. SARG have successfully mobilised their volunteers to collect large numbers of amphibian and reptile records across the county but this begs two questions. First, what does this information really tell about conservation status? Second, how do we turn 'dots on maps' into conservation action? Historically, a number of factors have impeded these connections, including the diversity of approaches to data collection, multiple data sources, variable data quality, outdated information, inconsistency in survey effort, and less effort on 'less popular' sites.

To address some of these inconsistencies, SARG have developed a new internet-based software solution for volunteer groups called 'ARGWEB'. This is an integrated system for survey support that fuses data sources including those from effort-based structured surveys and opportunistic recording, and builds heat maps using the Conservation Assessment Model (CASM 4) to show the distribution of different species. This information is also made available to land managers and planning authorities through specific data portals, allowing decision makers access to real time information about their sites that can be used to support sympathetic conservation management. For adders, the in-built simple distribution modelling can provide survey targets, and deduce conservation status up to county level. This includes status trends, which can be an independent check on whether appropriate conservation measures are in place or whether a re-think is required.

The final presentation of the meeting was from Jim Foster (Amphibian and Reptile Conservation). He reviewed the current situation and identified opportunities for the future. Adder declines appear to be driven by a number of factors including: ecological vulnerability due to the preference for mid-successional habitat, modest dispersal, and small populations; inadequate sectoral awareness and prioritisation; and poor public and political understanding and support. A major concern is the increasing pressure on land, and conflict with agri-environment schemes. The current uncertainty surrounding the future of farm subsidies and land management has major implications for the adder.
There is no single answer to this complex issue, and we need a broad-based, systemic approach to solve the problem. This will include changes in policy, informing changes in agrienvironment schemes notably the new Environmental Land Management Scheme (ELMS), better conservation practice and improved awareness through outreach programmes like 'Adders are Amazing!'. There is also a need to scale-up local good practice. Some measures are already being put in place with proposed revisions to SSSI selection criteria to include a single-species adder interest feature, protected sites need to be bigger, better and more joined up, and monitoring needs to be more objective and targeted. One issue that has arisen is the conflict between the needs of the adders and other site objectives, including species conservation, and recreational needs. One approach to reconciling these conflicts is through cross taxa projects, as currently demonstrated by the national 'Back from the Brink' programme and the 'Woodland Wildlife Toolkit'.

\section{DISCUSSION OF CONSERVATION THEMES}

During and after the meeting many potential components of adder conservation strategies were raised and discussed. Some of these are elaborated below.

\section{More attention to habitat management}

In Britain we have tended to focus our habitat conservation effort on hibernacula and springtime adder basking areas, and paid less attention to summer feeding areas. But, research shows that such feeding areas are very significant for the survival of immature animals; a key issue in adder demographics (Bauwens \& Claus, 2018). A shift in emphasis is required to ensure these are better preserved and that migration corridors between summer and winter areas are identified and retained by providing adequate cover for movement such as hedgerows and ecotones with complex sward. Climate change, especially summers with long hot dry periods, has been seen to have very negative impacts on adder populations, as reported by Thomas Madsen for 2018 in Sweden. Ina Blanke confirmed that in Germany adders can only exist in otherwise dry areas where there is some standing water. Consequently, retaining moisture in habitats, especially the crucial summer feeding areas, is an essential conservation effort. One approach may be to build more ponds on adder sites, as they have done in Germany, to offer drinking water and to increase the availability of amphibian prey.

More broadly, certain habitats could be designated as ARKs for adder conservation as suggested by Nigel Hand, who is currently working towards the development of ARK sites in the West Midlands. The advantage of such an approach would be that key adder sites are recognised, and management would prioritise adder conservation based on a detailed understanding of the adder populations present. In addition, the populations could be easily assessed for their suitability in providing specimens in support of the genetic or demographic enhancement of other sites.

It was suggested that better defined legislation is needed to ensure that planned burning is on a stronger 
environmental footing especially that it should be cyclical (every 7-10 years), there should be effective fire breaks, and a prescribed burning season. It is also clear that the public frequently present a problem and this raised the question of how best they should be engaged, and how access to sensitive areas can be limited. For limiting public access, one suggestion was the use of brash piles to help limit interactions between adders and dogs. They can also be used to channel people away from sensitive areas.

\section{Restoration of populations by genetic or demographic enhancement}

The 'Make the Adder Count' survey has highlighted the vulnerability of Britain's small and potentially isolated adder populations (Gardner et al., 2019). These may be at risk because their genetic diversity is too low, resulting in inbreeding depression, and/or because their demographics are unfavourable, i.e. their reproductive output is insufficient to prevent eventual extirpation. The solution to these two problems may not be the same. Greater genetic diversity can be achieved by adding new males to the population as described by Thomas Madsen (Madsen et al., 1999). Males are chosen for this purpose as they have the advantage of breeding every year, unlike females that generally only breed every second year. But if there is a demographic problem then the solution is to raise recruitment by adding more females to the population, although additional males might still be required. Nevertheless, each threatened population will have its own unique issues and may require an individually tailored solution beyond just bolstering the population. What life stage is released and at what time of year will probably depend largely upon what adders are available, and when. However, in the case of older subadults and adults the fixed behaviour patterns they develop within their natal habitats may make them a sub-optimal choice for release (Hodges \& Seabrook, 2019; Nash et al. 2018).

The genetic or demographic restoration of small isolated populations is potentially a vital component of the conservationist's toolkit. But such practice has not been fully researched and might present various risks including depletion of the donor population, death by disorientation/ predation to the individuals translocated, and transmission of disease or parasitic infection to the beneficiary population. Richard Griffiths summed this up as "...we are in the classic conservation dilemma of needing to make some important decisions based on incomplete evidence. Acting too hastily with only limited evidence could mean expensive mistakes; waiting until we have done more research may be too late. As a group we need to decide where on this spectrum we should intervene and how it will be resourced and implemented".

Under what circumstances and how population restorations should be attempted both require urgent consideration. The best way forward is likely to be through carefully controlled pilots that generate a body of evidence justifying enhancement. In the case of genetic enhancements, knowledge of the prior genetic condition of both donor and beneficiary populations should underpin at least the pilots. An important step to facilitate this would be to develop a genomic Single Nucleotide Polymorphism (SNP) toolkit with which to analyse samples in such a way that the data from different sites are comparable, leading to a robust database on the genetic health of adders. The genomic sequencing effort to develop the SNPs would be a one-off initiative separate from the recurring costs of genetic analysis of study populations. As to the source of adders for enhancements, mitigation projects are a potential option, although the pros and cons of such an approach need exploring in the context of a species management strategy. There are many commercial adder translocations undertaken in mitigation of development and offering translocation sites to ecological consultants based on welldefined conservation objectives is likely to be a considerable improvement on existing practice where there is generally no conservation objective other than avoiding immediate death at the development site. In the long-term, we need to build mitigation/receptor partnerships. This could be managed conveniently by an adder database and this could perhaps become a future function of the ARGWEB being developed by Steve Langham. More difficult is to ensure that these population enhancements are carefully monitored for a period long enough to determine whether restoration is sustainable. This could be limited to a demonstration of increased genetic diversity of immature animals within the first two or three years of enhancement, but demographic enhancements may take much longer requiring successful completion of the life cycle.

\section{Greater legal protection}

Concerns were expressed about the persecution of adders in France, although apparently there is no persecution in Sweden, which raises the question about the need to increase legal protection for adders and their habitats in Britain. There was general agreement that this is only worth doing if it is enforced. Smooth snakes and sand lizards are already European Protected Species (EPS), but both have suffered from planned habitat burns in the New Forest, and there has been no prosecution brought forward. Would it be any different for adders? Adders will only be truly safeguarded by a greater public awareness and sympathy and in part this could be generated by investment in projects such as 'Adders are Amazing!' that both engage the public and provide working material for celebrity naturalists and the media. Perhaps in time we can arrive at the happy situation in Sweden!

\section{Making the best of opportunities with environmental schemes}

It is believed that the current agro-environmental schemes are in some measure detrimental to wildlife but that the new Environmental Land Management System (ELMs) could offer a better alternative. It will pay farmers for environmental services and benefits, with pricing based on a natural capital valuation approach. The benefits include: improved air, water and soil quality, increased biodiversity, climate change mitigation, cultural benefits and better protection of historic environments. It is important that 
conservationists engage with the roll out of ELMs to obtain the best benefits for wildlife and particularly reptiles that must be included in biodiversity indices and/or targets.

\section{LOOKING FORWARD}

The meeting presented a wide range of actions for improvements in the conservation status of British adder populations and these should be considered as part of a national adder strategy. They included actions to:

- Create a National Adder Working Group (NAWG) to decide how to move conservation activities forward

- Link and co-ordinate those involved in adder research and land management in a larger informal Adder Network to ensure a free flow of ideas, information and advice between each other and the NAWG

- Set protocols or guidelines for genetic and demographic restoration of small populations, based on evidence from pilot studies, and implement genetic testing in a manner that data from different sites will be comparable

- Establish a suite of 'ARK' sites for focused adder conservation that can lead the way in establishing best practice

- Continue to gather data and monitor adders, to increase the volume of evidence available to pressure policy makers into action with regards to improving legislation and incorporating adders/reptiles in SSSI criteria and ELMS

- Engage with the proposed revisions to SSSI selection criteria to include an adder interest feature, and ensure that adders are better supported in areas where they are scarce or declining

- Achieve greater public sympathy for the species by further support to projects such as 'Adders are Amazing!'

- Investigate and support linking adder conservation actions to those of complementary species, for example butterflies such as the Pearl border fritillary and Duke of Burgundy, other reptiles and invertebrates, mammals, birds and plants

- Explore achievable approaches to more sympathetic management practices, such as finding alternatives to the inappropriate use of heavy machinery on important adder sites, managing bracken more sensitively, establishing the benefits of pond construction for adders, etc.

- Promote management strategies on adder sites that will result in carefully considered grazing timings and stock densities, and best practice for controlled on-site burns, and

- Initiate research into understanding and mitigating the impact of predators, particularly alien species such as wild boar and pheasants.

The problems identified in different countries/regions demonstrated similar themes including the negative impacts of infrastructure development and housing, intensive agriculture, the loss of good quality natural habitats, and climatic change, which are fragmenting populations and driving adders into smaller pockets. Furthermore, persecution in Britain and France is thought to have systematically reduced populations in some areas. In many countries of mainland Europe the adder is no longer widely distributed and, although large populations can be sustained on protected land, this depends on its continued protection and sympathetic site management. Indeed, it could be argued that across many parts of northern mainland Europe the adder can no longer be described as a 'widespread species'. Based on the evidence presented, it seems likely that this pattern could easily be repeated in Britain, with small and fragmented populations failing to thrive, and negative environmental factors reducing breeding success and juvenile recruitment. Without intervention, the adder could become a 'rare species', flourishing in just a few areas, such as Surrey and coastal Wales and Scotland, but vanishing elsewhere.

However, there is also good news. Collectively, we have a large body of knowledge and experience. There are many people championing the adder, representing a range of different disciplines: volunteers, NGOs, academic researchers, land owners, and statutory bodies, so the species will not slip away unnoticed. If we can gather and implement best practice, support and inform land owners, champion adders with local communities, and continue to gather sufficient evidence to prompt policy makers to include adders in any new wildlife legislation, then we may be able to halt the declines. And the chances of success will be all the stronger if we continue to share experience between ourselves and our European neighbours.

\section{ACKNOWLDEGMENTS}

The meeting would not have been possible without the help of Natasha Savage, Rhiannon Carys Williams, Matt Legg, Charlie Towler and Andrea Pozzi from Bangor University Herpetological Society/North West Wales ARG. We owe our gratitude to the North Wales Wildlife Trust for field visits and to all the speakers, some of whom travelled from far, to share their knowledge and experience with us. We would also like to thank the meeting sponsors including: Esmée Fairbairn Foundation, Herpetologic Ltd., KRAG, SARG, NHBS Ltd, and Habitat Aid for their generous support. For this submission to the Herpetological Bulletin, Roger Meek kindly provided editorial support.

\section{REFERENCES}

ARG UK (2019) Vanishing Viper programme. https://www. arguk.org/get-involved/news/vanishing-viper-2019a-european-approach-to-developing-an-adderconservation-strategy (accessed July 2019)

Bauwens, D. \& Claus, K. (2018). Do newborn adders suffer mass mortality or do they venture in a collective hideand-seek game? Biological Journal of the Linnean Society 124: 99-112.

CRAN (2019) R:TRIM package http://cran.wustl.edu/web/ packages/rtrim/index.html (accessed July 2019)

CBS (NL) (2019) Documentation for R:TRIM. https://www. cbs.nl/en-gb/society/nature-and-environment/ 
indices-and-trends\%2d\%2dtrim\%2d\%2d (accessed July 2019)

Gardner, E., Julian, A., Monk, C. \& Baker, J. (2019). Make the Adder Count: population trends from citizen science survey of UK adders. Herpetological Journal 29: 57-70.

Hodges, R.J. \& Seabrook, C. (2019). Emigration and annual dispersal of the northern viper (Vipera berus) in a chalk grassland reserve. Herpetological Bulletin 148: 1-10.

Gleed-Owen, C. \& Langham, S. (2012). The Adder Status Project: A conservation condition assessment of the adder (Vipera berus) in England, with recommendations for future monitoring and conservation policy. Report to Amphibian and Reptile Conservation. ARC, Bournemouth, UK. 78 pp.
Madsen, T., Shine, R., Olsson, M. \& Wittzell, H. (1999). Restoring an inbred adder population. Nature 402: 3435.

Nash, D. \& Griffiths, R.A. (2018). Ranging behaviour of adders translocated from a development site. Herpetological Journal 28: 155-159.

Accepted: 23 August 2019 